\title{
Evaluating the User Experience of E-Learning in the Distance Education Program at Taibah University
}

\section{-Opportunities for Learner Interaction, Strategies for Improvement, and Student Attitudes about Electronically-Based Instruction}

\author{
Amani Abdulaziz Afghani ${ }^{1}$ \\ ${ }^{1}$ Family science, Taibah University, AL Madinah, Saudi Arabia \\ Correspondence: Amani A Afghani, Taibah University, Saudi Arabia.
}

Received: January 7, 2021

Accepted: February 12, 2021

Online Published: February 23, 2021

doi:10.5430/ijhe.v10n4p151

URL: https://doi.org/10.5430/ijhe.v10n4p151

\begin{abstract}
This study aims to assess the strengths and weaknesses of the Blackboard E-learning management system used in distance education programs at Taibah University in Madinah, Saudi Arabia. The study takes a descriptive approach, employing several survey tools to acquire data on various aspects of the e-learning experience from the point of view of student users, with the objective of informing university policy and decision making. Particular aspects of the e-learning experience considered include the role of e-learning in providing opportunities for learner interaction, the effectiveness of the various mechanisms for improving the e-learning experience, and overall attitudes toward e-learning. The results of the study show that there are statistically significant differences in the experiences and attitudes about e-learning among various demographic groups: namely, between students in different academic years, students in different academic departments, and between students that have received prior training in computers and those that have not. In light of the results, a number of recommendations are made. It is recommended that there be increased cooperation between the various sectors of higher education and pre-university education, to ensure the spread of the culture of distance education among learners before they join the university. Intercommunication about the e-learning experience between different universities is also recommended, as is the hiring by institutions of higher learning of distance education experts.
\end{abstract}

Keywords: e-learning, distance education, education management system, electronic education, educational system

\section{Introduction}

Throughout the world, rapid developments in information technology have produced profound changes in how the institutions of society operate. These developments have proceeded in tandem with similarly transformative developments in the social, economic and scientific spheres. Institutions of higher learning have pressed to keep pace with these rapidly changing conditions, the opportunities they create, and the challenges and obstacles they present. New methods of teaching and learning have emerged. Many universities have exploited developments in electronic communications to create educational systems capable of reaching learners in remote locations and under unconventional circumstances. These systems have the potential to deliver high-quality educational content that is accessible to more students, at lower costs, at convenient times and through a variety of media. They can help compensate for shortages of academic and training staff in some educational sectors through virtual classes, as well as provide support services in the educational process such as early registration, classroom management, building and distributing study schedules, and managing testing and evaluation systems. In their efforts to harness communications technology to accommodate a wide variety of circumstances and capabilities, institutions of higher education find themselves continually at the forefront of innovation.

Despite the many advantages and opportunities they offer, distance education and e-learning programs also face significant challenges. Technical difficulties related to the efficiency of communication networks and technological infrastructure, lack of availability of devices and programs, challenges in producing professional content as well the high costs associated with it, the intensive efforts required to qualify and train all parties to the educational process, and numerous other challenges have proved substantial obstacles for educational institutions trying to keep pace. Numerous studies have demonstrated that new methods and formats for education are needed to effectively employ 
advanced technology (AL- Jacir, 2008; Yassin and Melhem, 2011; Al Hawamdeh, 2011; Radi, Mervat, Shaheen and Ibrahim, 2010). To keep pace with developments, it is necessary that institutions of higher learning continuously review, evaluate and improve their e-learning programs: identifying and monitoring obstacles, and developing solutions to overcome them.

One potentially valuable source of information for identifying obstacles to effective e-learning and developing strategies to overcome them is to be found in the users of these systems. In particular, a better understanding of the realities of e-learning from the students' point of view, and of their attitudes about the e-learning experience, is a matter worthy of research and analysis. Such studies serve as important sources of information for university policy and decisions makers, aiding them in their efforts to provide support to the elements that are shown to be working, to address areas of weakness, and to shape the future of distance education programs. The present study will examine the experiences and attitudes of female students at Taibah University in Madinah, Saudi Arabia.

E-learning has attracted attention from many researchers. Though these studies focus on different aspects of the topic, and consider different academic curricula, they share the primary goal of reaching honest results that can be used in policy-making and decision-making. In general, most studies have focused on user experiences with e-learning systems, whether globally or in the Arab world. They all focus on the obstacles to the implementation of e-learning, and on the use of e-learning in distance education. Eman Al-Tawil (2012) considered academic problems facing female students of distance education at Imam Muhammad bin Saud Islamic University in Riyadh, and proposals to address them. The researcher used the descriptive survey method, using a questionnaire tool that she applied to all students enrolled in the distance education system. Her study found that distance education students were in agreement on the mechanisms proposed to improve e-learning. The most important of these mechanisms was the provision of qualified academic staff to quickly respond to inquiries electronically. Ghadeer Al-Mahmadi (2018) investigated the benefits realized, and challenges, faced by students using an electronic learning system (EMES) at King Abdulaziz University in Jeddah, Saudi Arabia, as perceived from the students' point of view. Applying a descriptive approach, Al-Mahmadi employed a questionnaire tool to collect data on a sample of students and faculty members. Al-Mahmadi found that the average benefit score realized by students was more than double the average score for difficulties. Torkul \& Altunisik (2013) surveyed 562 students at Sakarya University in ?? to investigate the degree of their acceptance for e-learning. The researchers identified six factors affecting student acceptance of e-learning systems. Finally, in their study "Perceptions of East Asian students towards personal privacy in e-learning", Wang and Yang (2014) surveyed nearly 800 students in China and Japan that were familiar with e-learning environments. The authors founds privacy to be a significant concern among the participants. Though some positive trends in this arena were observed, respondents nevertheless express concerns about the accessibility and use of such items as personal photos, postal addresses and phone numbers. Building on the work of these scholars, the author of the present study undertook a survey of female students at Taibah University in Madinah, pertaining to their experiences using the Blackboard e-learning system in the distance education program. The study was initiated with the formulation of several research questions, informed by the prior studies, which were used to organize and direct the research. Focus was, in particular, on the experiences and attitudes of female students.

\subsection{Study Questions}

To investigate student perceptions about the strengths and weaknesses of e-learning in distance education at Taibah University, and how these should inform policy making, the following four study questions were formulated.

1. What is the reality of the experience of using e-learning in the distance education program at Taibah University from the female students' point of view?

2. What is the role of e-learning in the distance education program at Taibah University in achieving interaction between learners from the female students' point of view?

3. What tools can be used to develop e-learning in the distance education program at Taibah University, from the viewpoint of female students?

4. What are the attitudes of female students toward e-learning in the distance education program at Taibah University?

\section{Methodology}

\subsection{Approach of the Study and Procedures}

The study follows a descriptive and analytical approach suitable for an investigation of an exploratory nature. Such an approach turns to observations of phenomena in circumstances where theory is lacking. It seeks to uncover 
relationships and suggest potential explanations for them. Accordingly, the four study questions were investigated through the administration of three questionnaire surveys to a sample of students: one survey to address study questions 1 and 2, and one survey each for study questions 3 and 4.

\subsection{Study Population and Sample}

The study population consisted of (144) female students taking courses in the College of Family Sciences (the researcher's workplace) at Taibah University in Madinah. The students came from a variety of academic disciplines, and had all taken courses through the Blackboard e-learning management system during the academic year 1441/1442 AH. Demographic data were collected on the participants, including academic year, specialization and department, level of familiarity with the Blackboard e-learning management system, and whether they had taken training courses on the use of computers and the Internet.

\subsection{Building Study Tools}

Three questionnaires (surveys) were administered to study participants. Survey one addressed study questions 1 and 2 , while surveys two and three addressed study questions 3 and 4, respectively. Each questionnaire survey consisted of a series of paragraphs (or questions) to which the students were to individually respond by means of the 5-point Likert scale (Strongly Agree - Agree - Neutral - Opposition - Strongly Oppose). Specific items in the questionnaires were designed to address one and only one aspect (or field) of the corresponding study question. To clarify the method, each questionnaire is discussed below, along with issues of reliability and validity.

2.3.1 Questionnaire One: Monitoring the Reality of E-Learning (Difficulties and Challenges), and Its Role in Achieving Interaction between Learners

The researcher designed the questionnaire, and included four main fields (axes), or aspects, of study questions 1 and 2. These fields include technical support and the readiness of the digital infrastructure, the experience of using the Blackboard e-learning management system, general support for e-learning programs and for spreading the culture of distance education, and the role of e-learning in achieving interaction between learners. The questionnaire consisted in its initial form of (41) items distributed among the main fields, with each item belonging to one and only one field. Before administration to students, several steps were taken to ensure that the questionnaire was well designed to address the study questions. These steps include content verification and reliability analysis.

\section{1) Content verification or apparent veracity "veracity of arbitrators"}

Questionnaire one was content-verified by presenting it in its initial form to a group of (3) arbitrators and specialists from the faculty of the College of Family Sciences at Taibah University. Arbitrators were asked to consider the clarity and comprehensiveness of the paragraphs, their diversity, and their validity (i.e. their ability to measure what they were designed to measure). Arbitrators were also asked to express their views on the extent to which each statement was related to the field or axis to which it belonged. The arbitration panel made a number of recommendations. Some paragraphs were excluded due to their similarity to other paragraphs. A number were adjusted for better wording or to correct grammatical issues. Some paragraphs were separated into two. After arbitration, the questionnaire consisted of (35) paragraphs distributed over the four fields.

\section{2) Reliability}

In order to ensure the reliability of questionnaire one, Cronbach's Alpha was calculated, along with the associated reliability factor. The results are presented in the table and equation below.

Table 1. Of the reliability coefficients "Alpha Cronbach" for the fields and axes of the first questionnaire

\begin{tabular}{lcc}
\multicolumn{1}{c}{ Field } & $\begin{array}{c}\text { No. of } \\
\text { Paragraphs }\end{array}$ & Alpha Cronbach \\
\hline $\begin{array}{l}\text { The first field: the reality of using e-learning at Taibah } \\
\text { University in terms of technical support and the readiness of } \\
\text { the digital infrastructure. }\end{array}$ & 10 & 0.833 \\
The second field: Difficulties of using distance education in \\
relation to experience in using the Blackboard e-learning \\
management system \\
The third field: the difficulties of using distance education \\
in terms of supporting e-learning programs and spreading
\end{tabular}


the culture of distance education.

The fourth field: the role of e-learning in achieving $\quad 10 \quad 0.773$ interaction between learners.

Total

35

0.814

$$
=\sqrt{ } 0.814=0.902
$$

These values indicate a high degree of reliability for questionnaire one.

\subsubsection{Questionnaire Two: Monitoring Mechanisms to Improve the E-Learning System}

The researcher designed the questionnaire, and included two main fields (axes) for study question 3, regarding students' views on the tools that might be used for the further development of e-learning in distance education. The two fields for study question 3 were mechanisms for developing e-learning at the level of strategic planning and procedures, and mechanisms for developing e-learning at the level of training and technical support. The questionnaire consisted in its initial form of (31) items distributed among the two main fields, with each item belonging to one and only one field. Again, before administration to students, questionnaire two was subjected to content verification by a panel of arbitrators and to reliability analysis.

1) Content verification or apparent veracity "veracity of arbitrators"

Content verification for questionnaire two was achieved using the same means as questionnaire one. After adjustments in accordance with the recommendations of the arbitration panel, questionnaire two consisted of (20) paragraphs distributed over the two fields.

2) Reliability

In order to ensure the reliability of questionnaire two, Cronbach's Alpha was calculated, along with the associated reliability factor. The results are presented in the table and equation below.

Table 2. The reliability coefficients of "Alpha Cronbach" for the fields and axes of the second questionnaire

\begin{tabular}{ccc}
\hline Field & $\begin{array}{c}\text { No. of } \\
\text { Paragraphs }\end{array}$ & Alpha Cronbach \\
\hline $\begin{array}{l}\text { The first field: mechanisms for developing e-learning at the } \\
\text { level of strategic planning and procedures. }\end{array}$ & 10 & 0.862 \\
$\begin{array}{l}\text { The second field: mechanisms for developing e-learning at } \\
\text { the level of training and technical and technical support. } \\
\text { Total }\end{array}$ & 10 & 0.831 \\
\end{tabular}

$$
=\sqrt{ } 0.842=0.918
$$

These values indicate a high degree of reliability for questionnaire two.

2.3.3 Questionnaire Three: Measuring the Attitudes of Female Students at Taibah University towards the Use of Electronic Education

The researcher designed the questionnaire, and included one field (axis) for study question 4 regarding students' attitudes about the use of electronic education. The questionnaire consisted in its initial form of (22) items. Again, before administration to students, questionnaire three was subjected to content verification by a panel of arbitrators and to reliability analysis.

1) Content verification or apparent veracity "veracity of arbitrators"

Content verification for questionnaire three was achieved using the same means as questionnaires one and two. After adjustments in accordance with the recommendations of the arbitration panel, questionnaire three consisted of (20) paragraphs distributed over the single field.

2) Reliability

In order to ensure the reliability of questionnaire three, Cronbach's Alpha was calculated, along with the associated reliability factor. The results are presented in the table and equation below. 
Table 3. Reliability coefficients of "Alpha Cronbach" for questionnaire three

\begin{tabular}{ccc}
\hline Scale & $\begin{array}{c}\text { No. of } \\
\text { Paragraphs }\end{array}$ & Alpha Cronbach \\
\hline Total & 20 & 0.822 \\
\hline
\end{tabular}

$$
=\sqrt{ } 0.822=0.907
$$

These values indicate a high degree of reliability for questionnaire three.

\section{Data Analysis and Results}

To add greater depth to the study results, participants were divided into groups on the basis of several demographic variables, and comparisons were made, for each variable, between the responses at the different levels. In particular, it was investigated whether statistically significant differences were observed in participant responses along the levels of the following demographic variables: academic year of participant (second through fourth), academic department of the participant, and degree of training the participant had received in the use of computer technology. As participant responses were in the form of a five-point Likert scale (coded 1 to 5), quantitative analysis could be employed. Specifically, the following statistical hypotheses were formulated and tested using the survey data. Tests were in the form of a one-way Analysis of Variance (ANOVA) or one-sample T test, as appropriate.

1. There are statistically significant differences at the level (0.05) between the averages of female students' views on the reality of using e-learning in the distance education program at Taibah University and its role in achieving interaction between learners attributable to the variables (academic year - academic specialization and the department - obtaining training courses in Computer).

2. There are statistically significant differences at the level $(0.05)$ between the averages of female students' views on ways and mechanisms for developing e-learning in the distance education program at Taibah University, attributable to the variables (academic year - academic specialization and the department obtaining training courses in Computer).

3. Statistically significant differences at the level of (0.05) between the averages of female students' attitudes towards using e-learning in the distance education program at Taibah University attributable to the variables (academic year - academic specialization and the department - obtaining training courses in Computer).

\section{Hypothesis 1: student views on the e-learning user experience and on learner interaction}

1. Depending on the academic year variable

Results suggest a statistically significant difference at the level of (0.05) between the average responses from questionnaire one on the basis of academic year of the participant. Post-hoc tests show that participants in their third academic year had a significantly higher average response than the other groups, but that the average responses of the remaining groups were not significantly different.

Table 4. Results of the F-test for differences attributable to the variable of academic year

\begin{tabular}{cccc}
\hline F-test & Second group & Third group & Fourth group \\
\hline$* * 14.181$ & 3.645 & 3.922 & 3.627 \\
\hline
\end{tabular}

2. Depending on the variable of specialization and department

Results suggest a statistically significant difference at the level of (0.05) between the average responses from questionnaire one on the basis of academic department/specialization. Post-hoc tests show that participants in the department of Interior Design had a significantly higher average response than those of the other academic departments, with the remaining departments showing no significant differences.

Table 5. Results of the F test for the differences attributable to the variable of specialization and department

\begin{tabular}{cccc}
\hline F-test & $\begin{array}{c}\text { Housing, management } \\
\text { of institutions }\end{array}$ & Fashion Design & Interior Design \\
\hline$* * 11.298$ & 3.629 & 3.644 & 3.889 \\
\hline
\end{tabular}

3. Depending on whether the student had taken training courses in computer

Results suggest a statistically significant difference at the level of (0.05) between the average responses from 
questionnaire one on the basis of whether the participant had taken one or more computer training courses. The tests shows that participants who had not taken computer training had a significantly higher average response than those who had received such training.

Table 6. Results of the T- test for the differences attributable to the variable of obtaining computer training courses

\begin{tabular}{ccc}
\hline T-test & Average "Yes" & Average "No" \\
\hline$* * 7.227$ & 3.633 & 3.927
\end{tabular}

\section{Hypothesis 2: students' views on mechanisms for developing e-learning in the distance education program at} Taibah University

1. According to the academic year variable

Results suggest a statistically significant difference at the level of (0.05) between the average responses from questionnaire two on the basis of academic year of the participant. Post-hoc tests show that participants in their third academic year had a significantly higher average response than the other groups, but that the average responses of the remaining groups were not significantly different.

Table 7. Results of F-test for differences attributable to academic year variable

\begin{tabular}{cccc}
\hline F-test & Second group & Third group & Fourth group \\
\hline$* * 16.119$ & 3.552 & 3.879 & 3.573
\end{tabular}

2. Depending on the variable of specialization and department

Results suggest a statistically significant difference at the level of (0.05) between the average responses from questionnaire two on the basis of academic department/specialization. Post-hoc tests show that participants in the department of Interior Design had a significantly higher average response than those of the other academic departments, with the remaining departments showing no significant differences.

Table 8. Results of the F-test for the differences attributed to the variable of specialization and department

\begin{tabular}{cccc}
\hline F-test & $\begin{array}{c}\text { Housing, management } \\
\text { of institutions }\end{array}$ & Fashion Design & Interior Design \\
\hline$* * 14.253$ & 3.529 & 3.622 & 3.897 \\
\hline
\end{tabular}

3. Depending on whether the student had taken training courses in computer

Results suggest a statistically significant difference at the level of (0.05) between the average responses from questionnaire two on the basis of whether the participant had taken one or more computer training courses. The tests shows that participants who had not taken computer training had a significantly higher average response than those who had received such training.

Table 9. Results of the T-test for the differences attributable to the variable of taking courses in the computer

\begin{tabular}{ccc}
\hline T-test & Average "Yes" & Average "No" \\
\hline$* * 9.179$ & 3.588 & 3.837 \\
\hline
\end{tabular}

\section{Hypothesis 3: Student attitudes about e-learning}

1. According to the academic year variable

Results suggest a statistically significant difference at the level of (0.05) between the average responses from questionnaire three on the basis of academic year of the participant. Post-hoc tests show that participants in their third academic year had a significantly higher average response than the other groups, but that the average responses of the remaining groups were not significantly different.

Table 10. Results of F-test for differences attributable to academic year variable

\begin{tabular}{cccc}
\hline F-test & Second group & Third group & Fourth group \\
\hline$* * 15.228$ & 3.634 & 3.722 & 3.979 \\
\hline
\end{tabular}

2. Depending on the variable of specialization and department

Results suggest a statistically significant difference at the level of (0.05) between the average responses from questionnaire three on the basis of academic department/specialization. Post-hoc tests show that participants in the 
department of Interior Design had a significantly higher average response than those of the other academic departments, with the remaining departments showing no significant differences.

Table 11. Results of the F-test for the differences attributable to the variable of specialization and department

\begin{tabular}{cccc}
\hline F-test & $\begin{array}{c}\text { Housing, management } \\
\text { of institutions }\end{array}$ & Fashion Design & Interior Design \\
\hline$* * 10.596$ & 3.572 & 3.597 & 3.736 \\
\hline
\end{tabular}

3. Depending on whether the student had taken training courses in computer

Results suggest a statistically significant difference at the level of (0.05) between the average responses from questionnaire three on the basis of whether the participant had taken one or more computer training courses. The test shows that participants who had not taken computer training had a significantly higher average response than those who had received such training.

Table 12. Results of the T-test for the differences attributed to the variable of taking courses in the computer

\begin{tabular}{ccc}
\hline T-test & Average "Yes" & Average "No" \\
\hline$* * 8.332$ & 3.588 & 3.837
\end{tabular}

\section{Survey Results}

1. Respondents generally gave high scores for technical support and readiness of the digital infrastructure.

2. Responses indicate an moderate level of difficulty using the Blackboard e-learning management system.

3. Respondents generally gave low scores for the general level of support for e-learning programs and for the spreading of the culture of distance education.

4. The role of e-learning in achieving interaction between learners received high scores.

5. Tools and mechanisms for developing e-learning at the level of procedures and strategic planning received high scores.

6. Tools and mechanisms for developing e-learning at the level of training and technical support received high scores.

7. High scores on questionnaire three indicate female students exhibit generally positive attitudes towards the use of electronic learning management systems.

8. Students in the third year of university study showed a significantly higher average response on questionnaire one (the experiences of e-learning users and the role of e-learning in promoting learner interaction) than students in other academic years, with the remaining year groups showing no significant differences.

9. Students in the department of Interior Design showed a significantly higher average response on questionnaire one (the experiences of e-learning users and the role of e-learning in promoting learner interaction) than students from other departments, with the remaining departments showing no significant differences.

10. Students who had no courses in the use of computers showed a significantly higher average response on questionnaire one (the experiences of e-learning users and the role of e-learning in promoting learner interaction) than students who had had such courses.

11. Students in the third year of university study showed a significantly higher average response on questionnaire two (tools and mechanisms for developing e-learning in the distance education program) than students in other academic years, with the remaining year groups showing no significant differences.

12. Students in the department of Interior Design showed a significantly higher average response on questionnaire two (tools and mechanisms for developing e-learning in the distance education program) than students in other departments, with the remaining departments showing no significant differences.

13. Students who had no courses in the use of computers showed a significantly higher average response on questionnaire two (tools and mechanisms for developing e-learning in the distance education program) than students who had had such courses. 
14. Students in the third year of university study showed a significantly higher average response on questionnaire three (attitudes toward using e-learning in distance education) than students in other academic years, with the remaining year groups showing no significant differences.

15. Students in the department of Interior Design showed a significantly higher average response on questionnaire three (attitudes toward using e-learning in distance education) than students in other departments, with the remaining departments showing no significant differences.

16. Students who had no courses in the use of computers showed a significantly higher average response on questionnaire three (attitudes toward using e-learning in distance education) than students who had had such courses.

\section{Discussion}

Analysis of the data obtained from the student surveys has shed light on all of the study's research questions. Study question one pertained to the experience of using the e-learning system at Taibah University. Respondents showed a high degree of satisfaction with the promptness of responses to learners' inquiries. This promptness made it easier to engage in discussion, ask questions and share ideas (i.e. to take full advantage of the e-learning tools). Respondents also showed a high degree of satisfaction with technical support and with the readiness of the digital infrastructure. This is a key observation, as the digital infrastructure serves as the basic environment for electronic learning. These results are in agreement with those of Yang and Wang (2014) and with those of Hantoly (2016).

Study question two pertained to the role that e-learning plays in encouraging meaningful interaction between learners. Respondents showed a high degree of satisfaction with the opportunities for learner interaction in e-learning environments. e-Learning tools such as forums, discussion sessions and various other dialogue-type interactions provide an educational environment in which opinions and ideas are freely exchanged, and in which students can develop teamwork skills. The e-learning environment accelerates the process of communication, and allows for interaction outside official working hours and in informal settings. e-learning thus gives female students that are coming from different cultural environments and social conditions, and with diverse personal characteristics, a space of freedom in which many of the common obstacles to effective and comfortable communication are removed. These results are in agreement with the study of Aisan and Al-Ani (2007), confirming the ability of e-learning to bridge the gap between learners, and between learners and faculty. It also agrees with the results of Seddon \& Biasutti (2009), confirming the effectiveness of e-learning in increasing learners' interaction.

Study question three pertained to mechanisms for further developing e-learning systems and overcoming the most important difficulties and obstacles to their use. The results highlight the necessity for continuous study and review of the needs of students, as well as the needs of the labor market. In general, the results indicate a high degree of satisfaction among students with the tools and mechanisms for developing the e-learning system in terms of procedures and strategic planning. This result might be attributed to the continuous development and modernization processes carried out by Taibah University. The institution has undergone a number of successive technical transformations, as part of a serious attempt to solve the problems that e-learners face. These efforts include upgrades to servers and support devices, as well as the issuance of various applications and versions of software. In this way, the university has greatly facilitated the process of accessing the system through various devices with a minimum of distress, in addition to providing technical support and technical assistance to learners and faculty members. The results confirm the work of Ibrahim (2010) and of Abdel-Wahab (2012).

Study question 4 pertained to the attitudes of female students toward e-learning in distance education. The results indicate a high level of interest in e-learning among the study sample. These findings are in agreement with those of Mehra \& Omidia (2011), Siirak (2011), and Awad Ogal (2010). The overall high level of interest may be attributed to a number of potential factors. The integral role that technology has come to play in daily life has undoubtedly contributed. The unusual circumstances brought about by COVID-19 is likely another contributing factor.

Finally, it is noted that confirmation of the statistical hypotheses lends support to the survey results by lending credence to the basic assumptions of the study.

\section{Conclusions}

In this study, the author has investigated the strengths and weaknesses of the Blackboard e-learning management system as it is employed in distance education at Taibah University in Madinah. The motivation for the research was the awareness that e-learning is becoming an increasingly common and popular option in distance education programs. The basic approach was to survey a sample of students about their views on various aspects of the e-learning experience, and to present the lessons learned from their responses to university policy makers to aid in 
informing their decisions. Survey participants were questioned about the reality of using the Blackboard LMS e-learning management system. They were specifically asked to rate their experiences with Blackboard using a Likert scale with regard to several aspects of the experience: e-learning's role in creating opportunities for interaction between learners, the mechanisms that are in place for improving the e-learning system, and general attitudes among students about the e-learning environment and the culture of e-learning.

The results of the survey highlight areas where the e-learning system seems to be performing very well, and also suggests areas that might be improved. One area in which progress might be made is in the employment of e-learning for subjects or activities that are typically of a more hands-on nature (labs, for example). The goal is to improve the mechanisms for presenting academic subjects of a practical nature in e-learning management systems with the same level of competence with which more theoretical subjects are presented, so that the learner has opportunities to experiment, practice and observe in ways that are as effective as the comparable off-line experiences. The study also highlights the need to train and qualify faculty members in the employment of e-learning programs, along with training in modern teaching strategies and methods: what is known as "blended learning". It is noted that efforts should be made beginning in the first year of university enrollment to continuously train students to use computers and the Internet in an educational context. Such efforts will help students to acquire the skills and competencies needed to become successful users of e-learning systems, and endow them with the ability to overcome technical problems by themselves. It is also important that periodic updating of e-learning services and programs at the university continue with vigilance. This is necessary in order to keep pace with constant advances in information technology, and with anticipated increases in the number of e-learners that will put pressure on servers and other technical components of the e-learning system. Finally, the study highlights the need for additional training for the administrative staff that are responsible for various components of the e-learning system.

In light of the above observations, the study concludes with the following recommendations for further research.

1. Study the effectiveness of e-learning management systems in developing the various skills of learners and faculty members.

2. Study and evaluate the extent to which distance education programs at Taibah University adhere to comprehensive quality standards, whether at the level of learners, faculty members, administrators or technicians. The regular development of such standards, along with continuous review and evaluation of the system's efficiency as whole in light of those standards, should be research priorities.

\section{References}

Abdel-Wahab, Mohamed, Ali, \& Fikry (2012). Difficulties in using an e-learning management system model in some Egyptian universities from the viewpoint of faculty members and their students, an evaluation study. Journal of the College of Education, 78(2), Mansoura University.

Aisan, Salha, Al-Ani, \& Wajeh (2007). The reality of e-learning from the viewpoint of students of the College of Education at Sultan Qaboos University. Educational Science Studies, 34(4).

Al-Jasser, \& Ghada Bint A/rahman (2008). Challenges facing distance education in higher education institutions and the mechanisms for facing them from the viewpoint of faculty members at Taibah University. Master Thesis, College of Arts and Administrative Sciences, Umm Al-Qura University.

Al-Hawamdeh, \& Mohammad Fuad (2011). Obstacles to using e-learning from the faculty members' point of view at Al-Balqa Applied University. Damascus University Journal, 27(1-2).

Al-Mahmadi, \& Ghadeer Ali (2018). Evaluating the reality of using the electronic learning system (EMES) in the distance education program at King Abdulaziz University from the students' point of view. Journal of the College of Basic Education for Educational and Human Sciences, 39(2), 177-169. University of Babylon.

Al-Tawil, Ewan. Academic problems facing female students of distance education at Imam Muchammad bin Saud Islamic University and proposals to reduce them. Complimentary research to obtain a Master's degree in pedogogy, unpublished. College of Social Sciences, Imam Muchammad bin Saud Islamic University.

Al-Yahyouhi, \& Sabriya Salim (2011). Applying the regulatory requirements for e-learning at King Saud University from the point of view of educational leaders. Journal of the College of Education, 145(2), Al-Azhar University.

Awad, Ahmad, \& Fawaz (2010). The effect of using chat on student achievement in Nablus from the teachers' point of view. Al-Najah University Research Journal (Humanities), 24(4). 
Hantoly, Taghreed (2016). The reality of e-learning at An-Najah National University and its role in achieving interaction between learners from the viewpoint of students of the College of Graduate Studies, College of Education programs and members of the faculty. Master Thesis, College of Graduate Studies, An-Najah National University.

Ibrahim, J. Hassan (2010). Attitudes of students of the Educational Qualification Diploma at the Syrian Virtual University towards e-learning and its relationship to gender, specialization, computer experience and computer training courses: a survey. Journal of the Association of Arab Universities for Education and Psychology, 8(2), 94-124.

Kantoglu, B, O. Torkul, \& R. Altunisik (2013). Factors affecting students' satisfaction in E-learning model to analyze the proposal. Business and Economics Research Journal, 4(1), 121-141 (in Turkish)

Mehra, Vandana \& Omidian, Faranak (2011). Examining Students Attitudes toward E-Learning: A case from India. Malaysian Journal of Education Technology, 11(2), 13-18.

Radi, Mervat, Shaheen \& Ibrahim (2010). Obstacles to employing e-learning in the Technology Education Program and ways to overcome them at the Palestine Technical College in Deir al-Balah (case study). Research presented to the scientific conference (Technology Education and Educational Technology). Held in Palestine, Gaza: Al-Aqsa University 27-28 October 2010

Seddon, Fredrich \& Biasutti (2009). Evaluating a Music e-Learning resource: The Participants' Perspective. Computers and Education Online Journal, 53, 541-549. https://doi.org/10.1016/j.compedu.2008.12.011

Siirak, Virve (2011). Moodle E-Learning Environment as an Effective Tool in University Education. Online Journal of Information Technology and Application in Education, 1(2), 94-96.

Yang Fang \& Wang, Shudong (2014). Students Perception toward Personal Information and Privacy Disclosure in E-Learning. The Turkish Online Journal of Education Technology, 13(1), 207-216. https://doi.org/10.1037/t44647-000

Yassin Mahmoud \& Wang, Melhem, Muhammad (2011). Obstacles to the use of e-learning facing teachers in the Education Directorate of the First Irbid District. The Palestinian Journal of Open Distance Education, 3(5), Al Quds Open University, Palestine.

\section{Copyrights}

Copyright for this article is retained by the author(s), with first publication rights granted to the journal.

This is an open-access article distributed under the terms and conditions of the Creative Commons Attribution license (http://creativecommons.org/licenses/by/4.0/). 